\title{
Factors Impacting Tanzanian Rural and Peri-urban Drug Dispensaries' Perceived Benefits from Using an mHealth Reporting System
}

\author{
Alistair Elias \\ Master's Student, Department of Computer Science and Engineering, \\ University of Dar es Salaam \\ iD https://orcid.org/0000-0001-9852-3405
}

\author{
Joel S. Mtebe \\ Senior Lecturer, Department of Computer Science and Engineering, \\ University of Dar es Salaam \\ iD https://orcid.org/0000-0003-2760-7673
}

\begin{abstract}
This study examines the factors impacting Tanzanian drug dispensaries' perceptions of the potential benefits of using a mobile health (mHealth) reporting system. Since 2003, the Government of Tanzania has implemented its Accredited Drug Dispensing Outlet (ADDO) programme in support of dispensaries in underserved rural and peri-urban areas. A core element of this ADDO programme is the dispensary use of an mHealth application for reporting on the drugs they are dispensing and the medical conditions that are being treated. This study canvassed the views of ADDO programme dispensaries using the $\mathrm{mHealth}$ reporting system in the Iringa, Mbeya, and Njombe Regions, through a survey questionnaire completed by 318 dispensaries and focus group discussions with 38 dispensary personnel. The data revealed that four factors-system quality, information quality, service quality, and price value - are all having a statistically significant impact on dispensaries' perceptions of the potential benefits of using the mHealth system.
\end{abstract}

\section{Keywords}

mobile health (mHealth), online reporting, drug dispensaries, drug dispensing outlets, information systems, perceived benefits, updated D\&M IS success model, extended unified theory of acceptance and use of technology (UTAUT2), system quality, information quality, service quality, facilitating conditions, price value, Accredited Drug Dispensing Outlet (ADDO) programme, Tanzania, Iringa, Mbeya, Njombe

\section{Acknowledgement}

The authors acknowledge with gratitude the statistical advice provided by an anonymous reviewer.

DOI: https://doi.org/10.23962/10539/29193 


\section{Recommended citation}

Elias, A., \& Mtebe, J. S. (2020). Factors impacting Tanzanian rural and peri-urban drug dispensaries' perceived benefits from using an mHealth reporting system. The African Journal of Information and Communication (AJIC), 25, 1-22.

https://doi.org/10.23962/10539/29193

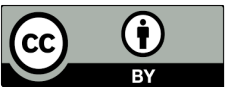

This article is licensed under a Creative Commons Attribution 4.0 International (CC BY 4.0) licence: https://creativecommons.org/licenses/by/4.0

\section{Introduction}

The use of mobile phone technology has rapidly expanded in developing countries due to decreases in the cost of connectivity and increases in network coverage (Chib et al., 2014). Researchers and governments have been taking advantage of these developments in the search for innovative ways to support healthcare provision (Aranda-Jan et al., 2014). Consequently, many mobile health (mHealth) projects have been implemented, which are aimed at: improving delivery processes, supply chain management of essential medical commodities, assisting policymakers in planning and implementing different programmes, providing remote access to healthcare facilities, facilitating the training of health workers, and enabling remote monitoring and surveillance (Chib et al., 2014; Leon, Schneider, \& Daviaud, 2012).

In Tanzania, the CommCare mHealth system helped home-based care providers to provide social support for patients with clinical symptoms associated with adverse drug events in Dar es Salaam (Bogan et al., 2009). The system was found to have improved the timeliness of home-based care visits by $86 \%$, thereby enhancing providers' performance (DeRenzi et al., 2012).

Similarly, the SMS for Life reporting system managed to prevent stock-outs of essential malaria drugs in nearly 5,000 Tanzanian health facilities (MikkelsenLopez et al., 2014). Users sent structured text messages to district-level supervisors at the end of each week to report their facilities' stock levels of anti-malaria drugs. Using this system, on average, only $29 \%$ of health facilities were completely stocked out of the first-line anti-malarials over a period of 15 months. Other examples of mHealth systems adopted in Tanzania include the systems developed for reporting of malaria in north-eastern Tanzania (Francis et al., 2017), for surveillance of malaria in Zanzibar (Barclay, Smith, \& Findeis, 2012), and for reducing maternal mortality in rural areas (Mbaruku et al., 2018).

More recently, the Ministry of Health and Social Welfare, through the Tanzania Food and Drugs Authority (TFDA) and a technical partner, Management Sciences for Health, implemented an mHealth reporting system to enable Accredited Drug Dispensing Outlet (ADDO) dispensaries to transmit information, on 
drugs dispensed and conditions treated, to the Ministry and the TFDA (Rutta et al., 2015). The ADDO programme aims to improve access to affordable, quality pharmaceutical services and drugs in rural areas with few or no registered pharmacies. This has been done by training retail drug store dispensary personnel to provide some prescription drugs (Embrey et al., 2016). However, it was found that many dispensaries were keeping data manually. Thus the data could not be easily reported to the regulators and the government authorities at the district, regional, and national Ministry level (Dillip et al., 2017). It was, therefore, difficult for the Ministry to assess ADDO dispensaries' performance and compliance with existing regulations. To address this problem, the mHealth system was implemented and integrated into the District Health Information Software 2 (DHIS2) platform to track and monitor data from dispensaries from various regions in Tanzania. Using this system, data on the movement of drugs that are being dispensed can easily be monitored, since dispensaries can send reports easily using their mobile devices. The system has been implemented in the Iringa, Mbeya, and Njombe Regions.

The study described and discussed in this article: (1) investigated the factors that impact dispensaries' perceptions of the potential benefits of using the ADDO programme's mHealth reporting system; and (2) generated recommendations for how the Tanzanian Government can improve dispensaries' experiences of using the system. The use factors explored by the research were drawn from the updated D\&M IS success model (DeLone \& McLean, 2003), and the extended unified theory of acceptance and use of technology (UTAUT2) (Venkatesh et al., 2003).

\section{Literature review}

\section{Tanzania's Accredited Drug Dispensing Outlet (ADDO) programme}

Traditionally in Tanzania, prescription drugs could be sold only by an authorised pharmacy, with a non-authorised retail drug store (known in Kiswahili as duka la dawa baridi $(D L D B))$ permitted to sell only non-prescription drugs. An increase in the number of health care seekers and private clinics (Chalker et al., 2015) triggered an increase in drug stores that illegally sold prescription drugs, especially in rural and peri-urban areas not served by authorised pharmacies. An estimated $10.5 \%$ of the lowest-income quartile of the country, representing $75 \%$ of Tanzanians, live in rural and peri-urban areas (Rutta et al., 2015).

To alleviate the problem, the Tanzania Food and Drug Authority (TFDA) launched a public-private programme called the Accredited Drug Dispensing Outlet (ADDO) programme, which aimed to train non-authorised retail drug store dispensaries to provide some prescription drugs (Rutta et al.,2009). Those stores would then acquire ADDO status (known in Kiswahili as duka la dawa mubimu (DLDM)). By 2016, there were over 9,000 shops across the country licensed as ADDOs by the TFDA (Embrey et al., 2016). 
Given the importance of ADDOs in Tanzania, the lack of reliable records on medicines and on the conditions for which the medicines were purchased became a concern to the Ministry (Rutta, 2014). It was difficult for supervisors and inspectors from the Ministry and the TFDA to assess ADDO dispensaries' performance and the shops' compliance with regulations, as most of the records were stored manually.

In 2018, the Ministry, through the TFDA, introduced the mHealth system under the Febrile Illness Management Project, which was established by the Ministry in conjunction with the National Malaria Control Programme and the Maternal, Newborn and Child Health Unit. The project aims to improve the diagnostic services and treatment for three febrile illnesses: malaria, diarrhea, and pneumonia. The mHealth system was established to monitor the project through the collection of information from the ADDOs. The project was launched in the Morogoro Region and is now also being implemented in the Mbeya, Iringa and Njombe Regions.

The system transmits data to a District Health Information Software version 2 (DHIS 2) platform for subsequent analysis and reporting. This system was acquired from the Integrated Disease Surveillance and Response (IDSR) system employed by the President's Malaria Initiative (PMI).This USAID-funded project aims to reduce malaria-related mortalities (PMI, 2017).

Nearly 1,000 ADDO shops have been registered for, and are using, the mHealth system in the Iringa, Mbeya, and Njombe regions. Since the system's introduction, these dispensaries have been recording information and sending it to the Ministry and the TFDA via their mobile phones. The system received positive reception during adoption, with the dispensaries initially using the system intensively, but there is anecdotal evidence to suggest that use has gradually diminished due to challenges faced by the ADDOs.

\section{mHealth information systems use}

The adoption and use of mHealth systems is becoming common in developing countries due to the decreasing cost and increasing network coverage of mobile services (Chib et al., 2014). However, studies have indicated that these systems often do not bring about their expected benefits (Aranda-Jan et al., 2014; Chang et al., 2011; Holden \& Karsh, 2010) as users tend to stop using them or to use relatively few features, beyond the period of intensive use after initial adoption (Kim, Lee, Hwang, \& Yoo, 2016). For instance, users started underreporting after some years of operation of the mHealth system implemented in Kenya (Githinji et al., 2013), and Uganda (Chang et al., 2011). This underutilisation of mHealth systems has been described as a partial failure (DeLone \& McLean, 2016; Heeks, 2006). 
While initial acceptance is an important step towards realising mHealth system success, long-term benefits depend on continued use (Bhattacherjee, 2001). Some studies have found that users tend to stop using the system or use relatively few features after a few years of use (Kim et al., 2016). As a result, achieving the intended long-term benefits of such systems is unlikely (Vaghefi \& Tulu, 2019). The success of information systems depends on users' continued use of the systems beyond the adoption stages (Karahanna, Straub, \& Chervany, 1999).

There has not been extensive research into how to ensure long-term benefits from mHealth system implementation (with Leon et al. (2012) being a notable exception). Aranda-Jan et al. (2014) argue that existing studies of $\mathrm{mHealth}$ systems in developing countries tend to focus on initial adoption and implementation, with little attention being paid to an evaluation of the long-term use of systems.

It is important to ensure that these systems are used beyond the adoption stages to reduce the chances of systems' failures (DeLone \& McLean, 2016). In addition, users must be able to use the majority of a system's features (Burton-Jones \& Volkoff, 2017), and it should be used habitually (Limayem, Hirt, \& Cheung, 2007). Currently, studies tend to focus on specific aspects of a system, project, or organisation during an evaluation of information system success, with little attention being paid to how the system is being used (DeLone \& McLean, 2016). As a result, the long-term benefits of mHealth systems adopted in developing countries remain uncertain (Aranda-Jan et al., 2014).

\section{Conceptual models for IS success and technology acceptance}

The two models deployed in the research were:

- $\quad$ the updated D\&M IS success model (DeLone \& McLean, 2013); and

- the extended unified theory of acceptance and use of technology

(UTAUT2) (Venkatesh, Thong, \& Xu, 2012).

The updated D\&M IS success model was extended from the original D\&M model (DeLone \& McLean, 1992). The original D\&M model consists of six factors: system quality, information quality, system use, user satisfaction, individual impact, and organisational impact. The updated D\&M model replaced individual impact and organisational impact with the net benefits, while service quality was added as a new factor (DeLone \& McLean, 2003).

The extended unified theory of acceptance and use of technology (UTAUT2) extends the original UTAUT order to study acceptance and use of technology in a consumer context (Venkatesh et al., 2012). The original UTAUT model has four key factors: performance expectancy, effort expectancy, social influence, and facilitating conditions that influence behavioural intention to use a technology and/or technology use. The UTAUT2 incorporates three factors into UTAUT: hedonic motivation, price value, and habit. Individual differences - namely, age, gender, and experienceare hypothesised to moderate the effects of these constructs on behavioural intention 
and technology use. Therefore, the UTAUT2 consists of seven factors, namely, effort expectancy, performance expectancy, facilitation conditions, social influence, price value, hedonic motivation, and habit.

These two models - the updated D\&M IS success model and UTAUT2widely used to understand the reasons for low or non-use of information systems in various contexts.

\section{Research design}

\section{Research model}

To explore the degree to which certain use factors may influence dispensaries' perceptions of the potential benefits of using the ADDO programme's mHealth system, relevant factors were extracted from the updated D\&M IS success model (DeLone \& McLean, 2013), and the extended unified theory of acceptance and use of technology (UTAUT2) model (Venkatesh et al., 2012) was adapted. Table 1 shows the main factors from two selected research models, and the five use factors that were found to be most relevant to the research's focus on perceived benefits of use (and thus adopted for the research model).

Table 1: Perceived-benefits-of-use factors adopted for the research model

\begin{tabular}{|c|c|c|}
\hline $\begin{array}{l}2 \text { models from the } \\
\text { literature }\end{array}$ & $\begin{array}{l}\text { Main factors identified in the } \\
2 \text { models in the literature }\end{array}$ & $\begin{array}{l}5 \text { perceived-benefits-of- } \\
\text { use factors adopted for the } \\
\text { research model }\end{array}$ \\
\hline $\begin{array}{l}\text { updated D\&M IS } \\
\text { success model } \\
\text { (DeLone \& McLean, } \\
\text { 2013) }\end{array}$ & $\begin{array}{l}\text { - } \quad \text { system quality } \\
\text { - } \quad \text { information quality } \\
\text { - } \quad \text { service quality }\end{array}$ & $\begin{array}{l}\text { 1. system quality } \\
\text { 2. information quality } \\
\text { 3. service quality }\end{array}$ \\
\hline $\begin{array}{l}\text { extended unified theory } \\
\text { of acceptance and use of } \\
\text { technology (UTAUT2) } \\
\text { model } \\
\text { (Venkatesh et al., 2012) }\end{array}$ & 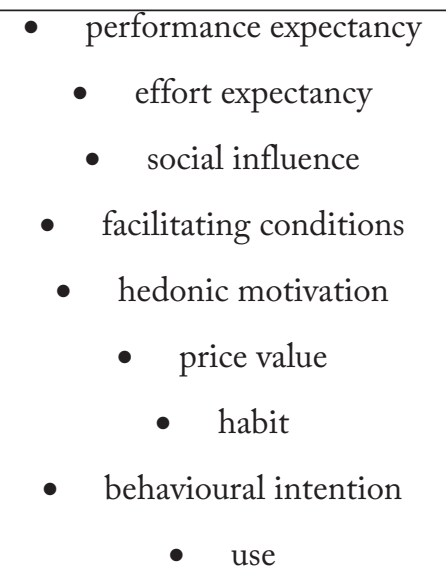 & $\begin{array}{l}\text { 4. facilitating conditions } \\
\text { 5. price value }\end{array}$ \\
\hline
\end{tabular}


Figure 1 provides a visualisation of the research model, with the five use factors chosen for the model — system quality, information quality, service quality, facilitating conditions, and price value-all contributing to perceived benefits of the use of an mHealth system.

Figure 1: Research model for investigating impacts on dispensaries' perceptions of potential benefits of using ADDO mHealth reporting system

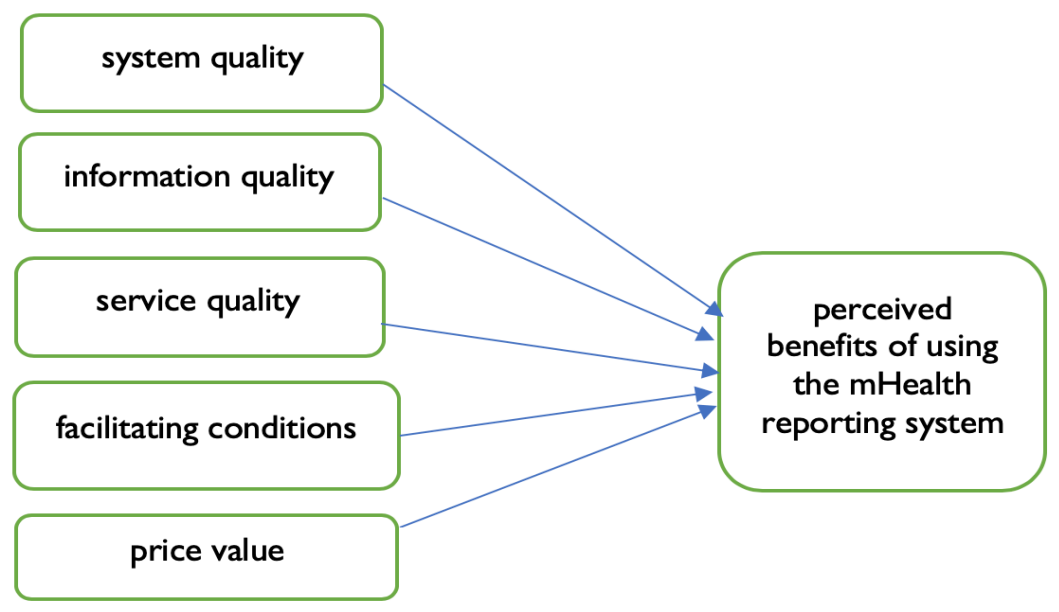

\section{Research hypotheses}

Hypotheses were developed for each of the five perceived-benefits-of-use factors in the research model.

\section{System quality}

System quality is concerned with whether or not there are "bugs" in the system, the consistency of the user interface, and the ease of use of the system (Seddon \& Kiew, 1995). The quality of an information system has been shown to have an impact on users' perceptions of it, as well as on users' satisfaction (DeLone \& McLean, 2013). Therefore, it was important to include system quality as a factor that will influence the ADDO programme dispensaries' perceptions of the potential benefits of using the $\mathrm{mHealth}$ system. The hypothesis for this perceived-benefits-of-use factor was:

H1: System quality has an impact on ADDO programme dispensaries' perception of the potential benefits of using the mHealth information system. 


\section{Information quality}

Moreover, the primary motivation of information systems is to provide users with accurate, timely, and relevant information (DeLone \& McLean, 2016). Therefore, information quality was considered an important factor in users' perception of the benefits of using the ADDO mHealth system. Information quality is the information system's output, which is determined by the quality of data and reports generated by the system (DeLone \& McLean, 2016). Dispensaries are likely to favourably perceive using the mHealth system if they find that the system generates quality data and reports that meet their needs. The hypothesis for this perceived-benefits-of-use factor was:

H2: Information quality has an impact on ADDO programme dispensaries' perception of the potential benefits of using the mHealth information system.

\section{Service quality}

According to DeLone and Mclean (2003), system support service is the measure of the quality of support services that users receive from the IS department and IT support personnel. It is expected that users with good system support are likely to continue using the system (DeLone \& McLean, 2016). To ensure smooth use of the system, the Ministry of Health has a dedicated IT Unit that provides support to users of the mHealth system. It was important to measure the quality of support services offered by this IT Unit. The hypothesis for this perceived-benefits-of-use factor was:

H3: Service quality has an impact on ADDO programme dispensaries' perception of the potential benefits of using the mHealth information system.

\section{Facilitating conditions}

In the ADDO mHealth context, key facilitating conditions include access to mobile telephony, internet access, and related resources. Facilitating conditions were found to be key determinants of users' continued use of various systems such as those researched by $\mathrm{Ng}$ et al. (2015) and Smith and Motley (2010). The hypothesis for this perceived-benefits-of-use factor was:

H4: Facilitating conditions have an impact on ADDO programme dispensaries' perception of the potential benefits of using the mHealth information system. 


\section{Price value}

The price value is considered positive when using the system results in net cost benefits (Venkatesh et al., 2012). When the system was introduced, dispensaries were initially provided with free internet data bundles to facilitate training in the system and to get the project started. Since that initial period, there has been an expectation that dispensaries will use their resources to pay for the internet data needed to continue using the system, i.e., that dispensaries will be willing to bear the cost of using this system because they perceive that the system has direct benefits in their day-to-day activities. The price value was found to be a predictor in the use of the aforementioned SMS for Life reporting app in Tanzania (Mikkelsen-Lopez et al., 2014). Therefore, it was important to include price value as an important factor for this study. The hypothesis for this perceived-benefits-of-use factor was:

H5: Price value has an impact on ADDO programme dispensaries' perception of the potential benefits of using the mHealth information system.

\section{Data collection}

The data collection took place in November 2019, via (1) a self-administered questionnaire composed of closed-ended questions; and (2) focus group discussions. For both the questionnaire and the focus groups, the participants were representatives of ADDO programme dispensaries using the mHealth reporting system in the Iringa, Mbeya, and Njombe Regions.

\section{Questionnaire}

Questionnaire respondents were asked to respond to statements using a fivepoint Likert scale ( 1 =strongly disagree; $2=$ disagree; $3=$ neutral; $4=$ agree; $5=$ strongly agree). The statements, provided in Table 2, were grounded in the updated D\&M IS success model (DeLone \& McLean, 2013) and the extended unified theory of acceptance and use of technology (UTAUT2) model (Venkatesh et al., 2003), with modifications necessary to fit the context of this particular study. Table 2 shows the non-demographic elements of the questionnaire. 
Table 2: Contents of the questionnaire

\begin{tabular}{|c|c|c|}
\hline Factor & Code & Item \\
\hline \multirow{4}{*}{ system quality } & SQ1 & The mHealth system is easy to learn. \\
\hline & SQ2 & The mHealth system is easy to use. \\
\hline & SQ3 & $\begin{array}{l}\text { The mHealth system requires only the minimum number } \\
\text { of fields and screens to enter data and generate the required } \\
\text { reports. }\end{array}$ \\
\hline & $\mathrm{SQ} 4$ & $\begin{array}{l}\text { The mHealth system includes the necessary features and } \\
\text { functions for performing my day-to-day activities. }\end{array}$ \\
\hline \multirow{6}{*}{$\begin{array}{l}\text { info. } \\
\text { quality }\end{array}$} & IQ1 & $\begin{array}{l}\text { The data, information, and reports that I receive from the } \\
\text { mHealth system are accurate. }\end{array}$ \\
\hline & IQ2 & $\begin{array}{l}\text { The mHealth system provides an output that is exactly what } \\
\text { is needed. }\end{array}$ \\
\hline & IQ3 & $\begin{array}{l}\text { The information that I receive from the mHealth system is } \\
\text { complete. }\end{array}$ \\
\hline & IQ4 & $\begin{array}{l}\text { Information and reports from the mHealth system are } \\
\text { readable, clear, and well-formatted. }\end{array}$ \\
\hline & IQ5 & $\begin{array}{l}\text { Information needed from the } \mathrm{mHealth} \text { system is always } \\
\text { available. }\end{array}$ \\
\hline & IQ6 & $\begin{array}{l}\text { The information that I receive from the mHealth system is } \\
\text { up to date. }\end{array}$ \\
\hline \multirow{4}{*}{ service quality } & SEQ1 & $\begin{array}{l}\text { IT Unit staff provide prompt support through various } \\
\text { communication means such as email, telephone, chat, etc. }\end{array}$ \\
\hline & SEQ2 & $\begin{array}{l}\text { The training provided by the IT Unit staff has enhanced my } \\
\text { ability to use the mHealth system. }\end{array}$ \\
\hline & SEQ3 & $\begin{array}{l}\text { The IT Unit staff are competent in the use of the mHealth } \\
\text { system. }\end{array}$ \\
\hline & SEQ4 & $\begin{array}{l}\text { The IT Unit staff have adequate knowledge to help me } \\
\text { when I experience any problems with the mHealth system. }\end{array}$ \\
\hline \multirow{4}{*}{$\begin{array}{l}\text { facilitating } \\
\text { conditions }\end{array}$} & $\mathrm{FC} 1$ & $\begin{array}{l}\text { I have the resources (e.g., mobile phone, Internet } \\
\text { connection, etc.) necessary to use the mHealth system. }\end{array}$ \\
\hline & $\mathrm{FC} 2$ & I have the knowledge necessary to use the mHealth system. \\
\hline & FC3 & $\begin{array}{l}\text { The mHealth system is similar to other systems I use for my } \\
\text { day-to-day activities. }\end{array}$ \\
\hline & $\mathrm{FC} 4$ & $\begin{array}{l}\text { Help is available when I get a problem with the mHealth } \\
\text { system. }\end{array}$ \\
\hline \multirow{3}{*}{ price value } & PV1 & The mHealth system is a good value for the money. \\
\hline & PV2 & $\begin{array}{l}\text { At the current cost of using the mHealth system, the system } \\
\text { provides good value. }\end{array}$ \\
\hline & PV3 & The cost I incur in using the mHealth system is reasonable. \\
\hline
\end{tabular}




\begin{tabular}{|l|l|l|}
\hline $\begin{array}{l}\text { perceived } \\
\text { benefits of } \\
\text { using the } \\
\text { mHealth } \\
\text { reporting } \\
\text { system }\end{array}$ & PB1 & $\begin{array}{l}\text { Using the mHealth system has improved information } \\
\text { quality in the Ministry. }\end{array}$ \\
\cline { 2 - 3 } & PB2 & $\begin{array}{l}\text { Using the mHealth system has improved daily information } \\
\text { management processes. }\end{array}$ \\
\cline { 2 - 3 } & PB3 & Using the mHealth system has reduced information errors. \\
\hline
\end{tabular}

The ADDO programme dispensaries targeted for the survey questionnaire were selected from all the wards in each region, to avoid sampling bias by including a disproportionately high number of stores from a few wards. To determine the minimum acceptable sample size for the questionnaire, the formula proposed by Green (1991) was adopted. That formula states that the minimum sample size should be $\mathrm{N}>50+8 \mathrm{~m}$, where $\mathrm{m}$ is the number of independent variables. The study had five factors. Therefore, the minimum sample size required for this research was $50+(8 * 5)=90$. Of the 500 potential respondents who were given the questionnaire in Iringa, Mbeya, and Njombe, 318 returned usable questionnaires. Of these 318 respondents, $64 \%$ were female, and $34 \%$ were male. Most $(87.1 \%)$ had attained secondary education, while $11.9 \%$ had primary education. A small fraction of the respondents had a tertiary education qualification (1\%).

\section{Focus group discussions}

Seven focus groups were convened-three in Iringa, two in Mbeya, and two in Njombe - and each group consisted of between five and eight participants, with a total of 38 respondents. The respondents who participated in the focus group discussions were selected from those who completed the questionnaire. The discussions aimed to check the validity of data obtained from the questionnaire and to get a broad range of viewpoints about the issues raised in the questionnaires. The focus groups focused on factors that were found to be significant and helped to identify additional factors that were influencing dispensaries' perceived benefits of using the ADDO mHealth reporting system.

\section{Data analysis}

The collected quantitative data was analysed to determine the relationships between the independent variables (system quality, information quality, service quality, facilitating conditions, and price value) and the dependent variable (perceived benefits of using the mHealth reporting system). The data obtained from focus group discussions were analysed by reviewing each focus group recording to identify commonalities across the responses.

\section{Questionnaire findings}

\section{Reliability testing}

The Cronbach's Alpha was used to test the reliability of the instrument. The Cronbach's Alpha coefficient of the 25 items was 0.917 ,indicating that the instrument was reliable as the value of Cronbach's Alpha was above 0.5. Furthermore, the result of Cronbach's Alpha for all six variables was above 0.5, as shown in Table 3. 
Table 3: Cronbach's Alpha coefficients for construct reliability measurement

\begin{tabular}{|c|c|c|c|}
\hline Factor & $\begin{array}{c}\text { Final number } \\
\text { of items }\end{array}$ & $\begin{array}{c}\text { Lowest } \\
\text { loading }\end{array}$ & $\begin{array}{c}\text { Cronbach's } \\
\text { Alpha }\end{array}$ \\
\hline system quality (SYSQ3 dropped) & 3 & 0.820 & 0.891 \\
\hline information quality & 4 & 0.687 & 0.847 \\
\hline service quality & 4 & 0.649 & 0.871 \\
\hline facilitating conditions & 3 & 0.665 & 0.572 \\
\hline price value & 3 & 0.743 & 0.775 \\
\hline $\begin{array}{c}\text { perceived benefits of using the mHealth } \\
\text { reporting system }\end{array}$ & 3 & 0.652 & 0.870 \\
\hline
\end{tabular}

\section{Correlation results}

Correlation between perceived benefits and the 5 dependent variables shows four of five are significant and positive (See Table 4). Only the facilitating conditions factor is not significant. Looking across the correlation matrix there are no correlations among the independent variables greater than 0.700 , therefore collinearity is not of great concern and all will proceed to be entered in multiple regression.

Table 4: Correlation matrix

\begin{tabular}{|c|c|c|c|c|c|c|c|}
\hline & & $\begin{array}{l}\text { perceived } \\
\text { benefits }\end{array}$ & $\begin{array}{l}\text { system } \\
\text { quality }\end{array}$ & $\begin{array}{l}\text { info. } \\
\text { quality }\end{array}$ & $\begin{array}{l}\text { service } \\
\text { quality }\end{array}$ & $\begin{array}{l}\text { facilitating } \\
\text { conditions }\end{array}$ & price value \\
\hline \multirow{3}{*}{$\begin{array}{l}\text { perceived } \\
\text { benefits }\end{array}$} & $\begin{array}{c}\text { Pearson } \\
\text { Correlation }\end{array}$ & 1 & $.488^{* * *}$ & $.600^{* *}$ & $.614^{* * *}$ & -.095 & $.492^{* * *}$ \\
\hline & $\begin{array}{c}\text { Sig. } \\
\text { (2-tailed) }\end{array}$ & & .000 & .000 & .000 & .092 & .000 \\
\hline & $\mathrm{N}$ & 318 & 318 & 318 & 318 & 317 & 318 \\
\hline \multirow{3}{*}{$\begin{array}{l}\text { system } \\
\text { quality }\end{array}$} & $\begin{array}{c}\text { Pearson } \\
\text { Correlation }\end{array}$ & $.488^{4 * *}$ & 1 & $.514^{* m}$ & $.561^{* * *}$ & -.035 & $.297^{\text {"*t+ }}$ \\
\hline & $\begin{array}{c}\text { Sig. } \\
\text { (2-tailed) }\end{array}$ & .000 & & .000 & .000 & .530 & .000 \\
\hline & $\mathrm{N}$ & 318 & 318 & 318 & 318 & 317 & 318 \\
\hline \multirow{3}{*}{$\begin{array}{c}\text { information } \\
\text { quality }\end{array}$} & $\begin{array}{c}\text { Pearson } \\
\text { Correlation }\end{array}$ & $.600^{* *+1}$ & $.514^{* * *}$ & 1 & $.689^{*+*}$ & .027 & $.341^{* *}$ \\
\hline & $\begin{array}{c}\text { Sig. } \\
(2-\text { tailed })\end{array}$ & .000 & .000 & & .000 & .637 & .000 \\
\hline & $\mathrm{N}$ & 318 & 318 & 318 & 318 & 317 & 318 \\
\hline \multirow{3}{*}{$\begin{array}{l}\text { service } \\
\text { quality }\end{array}$} & $\begin{array}{c}\text { Pearson } \\
\text { Correlation }\end{array}$ & $.614^{* *}$ & $.561^{* * *}$ & $.689^{* *}$ & 1 & .045 & $.412^{*+*}$ \\
\hline & $\begin{array}{c}\text { Sig. } \\
\text { (2-tailed) }\end{array}$ & .000 & .000 & .000 & & .428 & .000 \\
\hline & $\mathrm{N}$ & 318 & 318 & 318 & 318 & 317 & 318 \\
\hline
\end{tabular}




\begin{tabular}{|c|c|c|c|c|c|c|c|}
\hline \multirow{2}{*}{$\begin{array}{c}\text { facilitating } \\
\text { conditions }\end{array}$} & $\begin{array}{c}\text { Pearson } \\
\text { Correlation }\end{array}$ & -.095 & -.035 & .027 & .045 & 1 & $-.182^{* *}$ \\
\cline { 2 - 8 } & $\begin{array}{c}\text { Sig. } \\
(2-\text { tailed })\end{array}$ & .092 & .530 & .637 & .428 & & .001 \\
\cline { 2 - 8 } & $\mathrm{N}$ & 317 & 317 & 317 & 317 & 317 & 317 \\
\hline \multirow{3}{*}{ price value } & $\begin{array}{c}\text { Pearson } \\
\text { Correlation }\end{array}$ & $.492^{* *}$ & $.297^{* *}$ & $.341^{* *}$ & $.412^{* *}$ & $-.182^{* *}$ & 1 \\
\cline { 2 - 8 } & $\begin{array}{c}\text { Sig. } \\
(2-\text { tailed })\end{array}$ & .000 & .000 & .000 & .000 & .001 & 318 \\
\hline
\end{tabular}

\section{Identifying the factor structure}

Factor analysis was performed using the principal component analysis extraction method on 25 items, with the use of varimax rotation with Kaiser Normalization. Items with loadings greater than 0.3 on any of the factors (i.e., SQ3, IQ1, IQ6) were removed, and the analysis was re-run, as suggested by Samuels (2016). The loadings for each item are shown in Table 5.

Table 5: Factor loadings

\begin{tabular}{|c|c|c|}
\hline Factor & Items in varimax rotation & Loadings \\
\hline \multirow{3}{*}{ system quality } & SQ1 & 0.863 \\
\hline & $\mathrm{SQ} 2$ & 0.827 \\
\hline & SQ4 & 0.820 \\
\hline \multirow{4}{*}{ information quality } & IQ2 & 0.687 \\
\hline & IQ3 & 0.783 \\
\hline & IQ4 & 0.707 \\
\hline & IQ5 & 0.704 \\
\hline \multirow{4}{*}{ service quality } & SQ1 & 0.675 \\
\hline & $\mathrm{SQ} 2$ & 0.821 \\
\hline & SQ3 & 0.814 \\
\hline & SQ4 & 0.649 \\
\hline \multirow{3}{*}{$\begin{array}{l}\text { facilitating } \\
\text { conditions }\end{array}$} & FC1 & 0.665 \\
\hline & FC2 & 0.828 \\
\hline & FC3 & 0.683 \\
\hline \multirow{3}{*}{ price value } & PV1 & 0.787 \\
\hline & PV2 & 0.806 \\
\hline & PV3 & 0.743 \\
\hline \multirow{3}{*}{$\begin{array}{l}\text { perceived benefits } \\
\text { of using the } \\
\text { mHealth reporting } \\
\text { system }\end{array}$} & IU1 & 0.652 \\
\hline & IU2 & 0.835 \\
\hline & IU3 & 0.810 \\
\hline
\end{tabular}




\section{Hypothesis-testing}

The five hypotheses derived from the five factors in the research model-system quality, information quality, service quality, facilitating conditions, and price valuewere subjected to linear regression analysis using the SPSS software to predict the causal relationship between these factors and the dispensaries' perceptions of the potential benefits of using the mHealth system.

Using the enter method, a significant model emerged: $F(5,316)=63.915, \mathrm{p}<.001$. The model explains $49.9 \%$ of the variance (adjusted $\mathrm{R}^{2}=0.499$ ) in dispensaries' perceptions of the potential benefits of use of the mHealth system, as shown in Table 6.

Table 6: Summary of the research model extracted from SPSS

\begin{tabular}{|c|c|c|c|}
\hline Model & R & $\mathbf{R}^{2}$ & ${\text { Adjusted } \mathbf{R}^{2}}^{2}$ \\
\hline 1. & $0.712 \mathrm{a}$ & 0.507 & 0.499 \\
\hline
\end{tabular}

This model shows that $50.1 \%$ of the factors impacting the ADDO dispensaries' perceptions of the potential benefits of using the mHealth reporting system cannot be explained by factors proposed in this model. This is to say, the five factorssystem quality, information quality, service quality, facilitating conditions, and price value - can explain only $49.9 \%$ of factors impacting the dispensaries' perceptions of the mHealth reporting system in the Iringa, Mbeya and Njombe Regions.

In testing the hypotheses, the beta values indicated the contribution by each factor in the research model, after performing regression analysis using SPSS. The finding in respect of each hypothesis (i.e., the finding as to whether the factor in question had a positive or negative impact) was determined to be significant when the finding had a p-value (calculated probability) of less than 0.05 . The results from this study showed that, among the five factors presented in this study, four were found to be having a significant positive impact (i.e., their beta values were positive, at $\mathrm{p}$-values less than 0.05). The facilitating conditions factor was not found to be having a significant effect on dispensaries' perceptions of the potential benefits of using the mHealth reporting system, as its $\mathrm{p}$-value was not less than 0.05 . Table 7 provides the analysis of variance (ANOVA) values, and Table 8 provides a summary of beta values and $p$-values for the five factors, as obtained from a linear regression analysis. 
Table 7: ANOVA values

\begin{tabular}{|c|c|c|c|c|c|c|}
\hline Model & & $\begin{array}{c}\text { Sum of } \\
\text { squares }\end{array}$ & Df & $\begin{array}{c}\text { Mean } \\
\text { square }\end{array}$ & F & Sig. \\
\hline 1 & Regression & 82.693 & 5 & 16.539 & 63.915 & $.000^{\mathrm{b}}$ \\
\hline & Residual & 80.474 & 311 & .259 & & \\
\hline & Total & 163.167 & 316 & & & \\
\hline
\end{tabular}

Table 8: Standardised regression coefficients

\begin{tabular}{|c|c|c|c|c|}
\hline Construct & Standard error & Beta & P-value & $\begin{array}{c}\text { Implication of } \\
\text { p-value }\end{array}$ \\
\hline system quality & 0.046 & 0.128 & 0.010 & $\mathrm{p}<0.05$ \\
\hline $\begin{array}{c}\text { information } \\
\text { quality }\end{array}$ & 0.059 & 0.278 & 0.000 & $\mathrm{p}<0.05$ \\
\hline $\begin{array}{c}\text { service quality } \\
\text { facilitating } \\
\text { conditions }\end{array}$ & 0.058 & 0.253 & 0.000 & $\mathrm{p}<0.05$ \\
\hline price value & 0.040 & -0.065 & 0.115 & $\mathrm{p}>0.05$ \\
\hline
\end{tabular}

In Table 8 , system quality's significant positive impact is indicated by its positive beta and its $\mathrm{p}$-value being less than 0.05 (beta $=0.128, \mathrm{p}<0.05$ ). This finding implies that the surveyed dispensaries felt the mHealth system was of high quality and therefore it will bring higher benefits. Information quality's significant positive impact is shown by its positive beta and its $\mathrm{p}$-value of less than 0.05 (beta $=0.278, \mathrm{p}<0.05$ ). This finding suggests dispensaries perceived that the mHealth system generated quality reports for record-keeping as well as for sending the data to the higher authorities. Service quality's significant positive impact is indicated by its beta being positive and its $\mathrm{p}$-value being less than 0.05 (beta $=0.253, \mathrm{p}<0.05$ ). The lack of significant impact generated by the facilitating conditions factor is indicated by its $\mathrm{p}$-value being greater than 0.05 (beta $=-0.065, \mathrm{p}>0.05$ ). Price value's significant positive impact is indicated by its positive beta and its $\mathrm{p}$-value being less than 0.05 (beta $=0.242, \mathrm{p}$ $<0.05)$. This finding suggests dispensaries perceived that the cost associated with using the mHealth system was not a limiting factor. The five hypotheses and their beta values and p-values are shown in Table 9 . 
Table 9: Hypothesis-testing findings

\begin{tabular}{|c|c|}
\hline Hypothesis & Results \\
\hline $\begin{array}{c}\text { System quality has an impact on ADDO } \\
\text { programme dispensaries' perception of the } \\
\text { potential benefits of using the mHealth } \\
\text { reporting system. }\end{array}$ & $\begin{array}{c}\text { significant with positive effect (beta }= \\
\text { Information quality has an impact } \\
\text { on ADDO programme dispensaries' } \\
\text { perception of the potential benefits of } \\
\text { using the mHealth reporting system. }\end{array}$ \\
$\begin{array}{c}\text { Service quality has an impact on ADDO } \\
\text { programme dispensaries' perception of the } \\
\text { potential benefits of using the mHealth } \\
\text { reporting system. }\end{array}$ & significant with positive effect (beta $=$ \\
\hline $\begin{array}{c}\text { Facilitating conditions have an impact } \\
\text { on ADDO programme dispensaries' } \\
\text { perception of the potential benefits of } \\
\text { using the mHealth reporting system. }\end{array}$ & $0.278, \mathrm{p}<0.05)$ \\
\hline $\begin{array}{c}\text { Price value has an impact on ADDO } \\
\text { programme dispensaries' perception of the } \\
\text { potential benefits of using the mHealth } \\
\text { reporting system. }\end{array}$ & $0.253, \mathrm{p}<0.05)$ \\
\hline
\end{tabular}

\section{Focus group findings}

As a supplement to testing the hypotheses via the survey, the focus group discussions were conducted to gain more insight into the factors influencing dispensaries' perceptions of the potential benefits of using the mHealth information system. The focus groups focused on the four factors that were found via the questionnaire to have a statistically significant impact on the dispensaries' perceptions of the potential benefits: system quality, information quality, service quality, and price value.

\section{System quality}

In line with the survey finding that system quality had a significant positive impact on dispensaries' perceptions of the potential benefits of using the mHealth reporting system, there was consensus among the focus group participants that the mHealth system was more convenient to use than the system of filling in paper documents to send to the Ministry. In the words of one participant:

It is very convenient to use the system for preparing and sending the reports compared to the time when we were doing this manually. We were required 
to fill in the paper documents and send them to the Ministry. It was taking

a lot of time, and the chance of making errors was huge.

Another participant said:

I have to make a choice, to use the system for managing my office and sending the report electronically or fill in the paperwork. If you compare the benefits, I should learn and use this system.

Nonetheless, some dispensary personnel in the focus groups indicated that the system was difficult to use-because, among other things, it was slow, and it was difficult to see on a mobile device, given the size of the mobile screen. Some focus group participants indicated that they could not use most of the features of the system. Two of the focus group inputs were as follows:

The system is slow. It takes a bit of time to load the data once you click [the] send button.

The system is okay but look at my phone and the size of the screen. I have to take [out] my glasses every time I have to use this system. Maybe if they reduce the number of screens, it might be better.

Some dispensary personnel said they preferred using tablets rather than mobile phones, due to small screen sizes making data entry difficult.

\section{Information quality}

In keeping with the survey finding that information quality had a significant positive impact on dispensaries' perceptions of the potential benefits of using the mHealth reporting system, there was a consensus in the focus groups that the current system provided better quality information when compared to a paper-based system. However, focus group participants also pointed to potential information-quality improvements that could be made. According to one participant:

The system should be able to send feedback on our phones when we send monthly reports. This is missing in the current system.

In the words of another focus group participant:

It would be nice if the system can help me to see the items that are out of stock and are missed from the ordered quantity.

It was also found that some dispensaries wanted to be able to generate information reports for their own use, in addition to generating the reports in the formats required 
by the Ministry. For instance, dispensaries wanted to be able to keep records of their sales and stocks of the goods for their own use.

Some focus group participants said they sometimes had difficulty meeting the monthly reporting deadlines. It was suggested that notifications could be sent via SMS to remind dispensaries of the deadlines for submitting reports.

\section{Service quality}

Although the survey found that service quality had a significant positive impact on dispensaries' perceptions of the potential benefits of using the mHealth system, many participants in the focus groups were critical of what they saw as a lack of training support from the Ministry's IT Unit staff. It seems that the training that was conducted at the beginning of the mHealth project was not sufficient to enable dispensaries to use the system with full effectiveness. As a result, the majority of the focus group participants indicated that they needed more training. For instance, in the words of one participant:

My opinion is that this system is good, but I ask for the experts to give us more training, as the system has many features which we cannot use [...] properly. In the beginning, I had to spend time asking our friends in other shops [as to] how to send monthly reports, but later I mastered it. But the problem has remained in the stock module, in which I think I need more support.

Another participant said:

The IT staff should visit us more often to check if we have problems. Since they conducted this training [in 2017], it [has been] almost two years now, and I have not seen them. Look, now I have a lot to ask, but I cannot do it. The system is not very difficult to use, but I have so many ideas on how to improve it.

\section{Price value}

While the survey results pointed to the price value factor as having a significant positive impact on dispensaries' perceptions of the potential benefits of using the mHealth system, the sentiments in the focus groups were found to be mixed on the matter of cost. Many participants felt that the mHealth system had positive cost implications - a sentiment voiced by this participant:

I can save time and transportation costs [through] avoiding unnecessary trips to the central office to submit the printed forms. So, it is [really] important to use this system. 
However, at the same time, this same participant criticised the fact that although the system required internet access when sending reports to the Ministry, the cost of the internet was not covered by the Ministry. Other participants were also critical of the internet costs created by the system, indicating that the cost was a barrier to their dispensaries. In the words of one such participant:

On average, I can spend almost TSH2,000 [approximately USD1) for sending monthly reports. This is a lot of money for a small shop like this.

\section{Analysis and conclusions}

Based on the results of this study, we propose, in Figure 2, a four-factor model for understanding and addressing the factors currently impacting dispensaries' perceptions of the potential benefits of using the mHealth reporting system in Tanzania.

Figure 2: Factors impacting dispensaries' perceptions of potential benefits of using ADDO mHealth reporting system

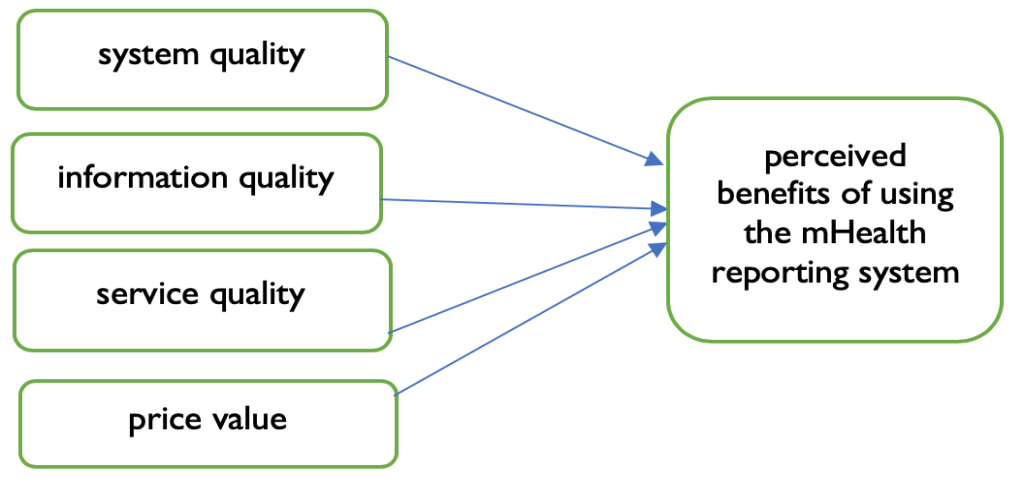

Our study provides clear evidence that four of the five factors, according to our survey results, have a significantly positive impact on dispensaries' perceptions of the potential benefits of using the mHealth reporting system. Despite these findings, the focus group discussions made it clear that there is still much room for improvements. In respect of system quality, the core focus group critiques, that the ADDO mHealth reporting system is too slow and that it is difficult to use on a mobile handset, certainly need to be addressed by the Ministry. In respect of price value, the chief difficulty is the lack of free internet provision to the dispensaries for use in their reporting. The implementers of mHealth projects need to find ways to provide subsidised or free internet use for the system's users. The ADDO programme's managers should negotiate with mobile firms for the provision of discounted or free internet services to the participating dispensaries. There are already precedents in Tanzania for such arrangements. In Zanzibar, for instance, mobile operator Airtel provided free internet services for users of an mHealth system aimed at reducing maternal mortality in rural Tanzania (Mbaruku et al., 2018). 
In respect of service quality, the focus group discussions indicated that the Ministry's training provision for dispensaries has not been sufficiently intensive. Building the perceived benefits of the system in the eyes of the dispensaries is, therefore, contingent on improved and ongoing training support from the Ministry's IT Unit. In respect of information quality, a shortcoming cited in the focus group discussions is the lack of provision for ADDO dispensaries to use the mHealth system to generate reports, not only for the Ministry, but also for their own use. To increase perceived benefit, the Ministry needs to build in the functionality necessary for dispensaries to customise reports to meet their own needs at the facility level.

\section{References}

Aranda-Jan, C. B., Mohutsiwa-Dibe, N., \& Loukanova, S. (2014). Systematic review on what works, what does not work and why of implementation of mobile health (mHealth ) projects in Africa. BMC Public Health, 14(188). https://doi.org/10.1186/1471-2458-14-188

Barclay, V. C., Smith, R. A., \& Findeis, J. L. (2012). Surveillance considerations for malaria elimination. Malaria Journal, 11, 2-5. https://doi.org/10.1186/1475-2875-11-304

Bhattacherjee, A. (2001). Understanding information systems continuance: An expectationconfirmation model. MIS Quarterly, 25(3), 351-370. https://doi.org/10.2307/3250921

Bogan, M., Mushi, C., Esch, J. Van, Wakabi, T., Lesh, N., Derenzi, B., \& Mitchell, M. (2009). Improving standards of care with mobile applications in Tanzania. In Presented at the W3C Workshop on the Role of Mobile Technologies in Fostering Social and Economic Development in Africa.

Burton-Jones, A., \& Volkoff, O. (2017). How can we develop contextualized theories of effective use? A demonstration in the context of community-care electronic health records. Information Systems Research, 28(3), 468-489. https://doi.org/10.1287/isre.2017.0702

Chalker, J. C., Vialle-Valentin, C., Liana, J., Mbwasi, R., Semali, I. A., Kihiyo, B., ... RossDegnan, D. (2015). What roles do Accredited Drug Dispensing Outlets in Tanzania play in facilitating access to antimicrobials? Results of a multi-method analysis. Antimicrobial Resistance and Infection Control, 4(1), 1-11. https://doi.org/10.1186/s13756-015-0075-2

Chang, L. W., Kagaayi, J., Arem, H., Nakigozi, G., Ssempijja, V., Serwadda, D., ... Reynolds, S. J. (2011). Impact of a mHealth intervention for peer health workers on AIDS care in rural Uganda: A mixed methods evaluation of a cluster-randomized trial. AIDS and Behavior, 15, 1776-1784. https://doi.org/10.1007/s10461-011-9995-x

Chib, A., Velthoven, M. H. Van, \& Car, J. (2014). mHealth adoption in low-resource environments : A review of the use of mobile healthcare in developing countries. Journal of Health Communication: International Perspectives, 20(1), 37-41. https://doi.org/10.1080/10810730.2013.864735

DeLone, W. H., \& McLean, E. R. (1992). Information systems success - the quest for a dependent variable. Information Systems Research, 3(1), 60-95. https://doi.org/10.1287/isre.3.1.60

DeLone, W. H., \& McLean, E. R. (2003). The DeLone and McLean model of information systems success: A ten-year update. Journal of Management Information Systems / Spring, 19(4), 9-30. https://doi.org/10.1080/07421222.2003.11045748 
DeLone, W. H., \& McLean, E. R. (2013). The DeLone and McLean model of information systems success : A ten-year update. Journal of Management Information Systems, 8(4), 9-30. https://doi.org/10.1080/07421222.2003.11045748

DeLone, W. H., \& McLean, E. R. (2016). Information systems success measurement. Foundations and Trends in Information Systems, 2(1), 1-116. https://doi.org/10.1561/2900000005

DeRenzi, B., Birnbaum, B., Findlater, L., Mangilima, J., Payne, J., Parikh, T., ... Lesh, N. (2012). Improving community health worker performance through automated SMS. In Proceedings of the Fifth International Conference on Information and Communication Technologies and Development (pp. 25-34). Atlanta, GA, USA. https://doi.org/10.1145/2160673.2160677

Dillip, A., Kimatta, S., Embrey, M., Chalker, J. C., Valimba, R., Malliwah, M., ... Johnson, K. (2017). Can formalizing links among community health workers, Accredited Drug Dispensing Outlet dispensers, and health facility staff increase their collaboration to improve prompt access to maternal and child care? A qualitative study in Tanzania. BMC Health Services Research, 17(1), 1-11. https://doi.org/10.1186/s12913-017-2382-1

Embrey, M., Vialle-Valentin, C., Dillip, A., Kihiyo, B., Mbwasi, R., Semali, I. A., ... RossDegnan, D. (2016). Understanding the role of accredited drug dispensing outlets in Tanzania's health system. PLOS ONE, 11(11), 1-16. https://doi.org/10.1371/journal.pone.0164332

Francis, F., Ishengoma, D. S., Mmbando, B. P., Rutta, A. S. M., Malecela, M. N., Mayala, B., ... Michael, E. (2017). Deployment and use of mobile phone technology for real-time reporting of fever cases and malaria treatment failure in areas of declining malaria transmission in Muheza district north-eastern Tanzania. Malaria Journal, 16(1), 1-14. https://doi.org/10.1186/s12936-017-1956-z

Githinji, S., Kigen, S., Memusi, D., Nyandigisi, A., Mbithi, A. M., Wamari, A., ... Zurovac, D. (2013). Reducing stock-outs of life saving malaria commodities using mobile phone text-messaging: SMS for Life study in Kenya. PLoS ONE, 8(1), 1-8. https://doi.org/10.1371/journal.pone.0054066

Green, S. . (1991). How many subjects does it take to do a regression analysis. Multivariate Behavioral Research, 26(3), 499-510. https://doi.org/10.1207/s15327906mbr2603 7

Heeks, R. (2006). Health information systems: Failure, success and improvisation. International Journal of Medical Informatics, 75(2), 125-137. https://doi.org/10.1016/j.ijmedinf.2005.07.024

Holden, R. J., \& Karsh, B. (2010). The Technology Acceptance Model : Its past and its future in health care. Journal of Biomedical Informatics, 43(1), 159-172. https://doi.org/10.1016/j.jbi.2009.07.002

Karahanna, E., Straub, D. W., \& Chervany, N. L. (1999). Information technology adoption across time: A cross-sectional comparison of pre-adoption and post-adoption beliefs. MIS Quarterly: Management Information Systems, 23(2), 183-213. https://doi.org/10.2307/249751

Kim, S., Lee, K., Hwang, H., \& Yoo, S. (2016). Analysis of the factors influencing healthcare professionals' adoption of mobile electronic medical record (EMR) using the unified theory of acceptance and use of technology ( UTAUT ) in a tertiary hospital. $B M C$ Medical Informatics and Decision Making, 16(12), 1-12. https://doi.org/10.1186/s12911-016-0249-8 
Leon, N., Schneider, H., \& Daviaud, E. (2012). Applying a framework for assessing the health system challenges to scaling up mHealth in South Africa. BMC Medical Informatics and Decision Making, 12(1). https://doi.org/10.1186/1472-6947-12-123

Limayem, M., Hirt, S. G., \& Cheung, C. M. K. (2007). How habit limits the predictive power of intention: The case of information systems continuance. MIS Quarterly: Management Information Systems, 31(4), 705-737. https://doi.org/10.2307/25148817

Mbaruku, G., Therrien, M. S., Tillya, R., Mbuyita, S., Mtema, Z., Kinyonge, I., ... Miller, S. (2018). Implementation project of the non-pneumatic anti-shock garment and $\mathrm{m}$-communication to enhance maternal health care in rural Tanzania. Reproductive Health, 15(1), 177. https://doi.org/10.1186/s12978-018-0613-5

Mikkelsen-Lopez, I., Shango, W., Barrington, J., Ziegler, R., Smith, T., \& DeSavigny, D. (2014). The challenge to avoid anti-malarial medicine stock-outs in an era of funding partners: The case of Tanzania. Malaria Journal, 13(1), 1-9. https://doi.org/10.1186/1475-2875-13-181

Ng, S. N., Matanjun, D., D’Souza, U. J. A., \& Alfred, R. (2015). Understanding pharmacists' intention to use medical apps. Electronic Journal of Health Informatics, 9(1), 1-17.

Rutta, E. (2014). Medicines in Health Systems : Advancing access, affordability, and appropriate use. Alliance for Health Policy and Systems Research Flagship Report 2014. https://doi.org/ISBN 9789241507622

Rutta, E., Liana, J., Embrey, M., Johnson, K., Kimatta, S., Valimba, R., ... Sillo, H. (2015). Accrediting retail drug shops to strengthen Tanzania's public health system: An ADDO case study. Journal of Pharmaceutical Policy and Practice, 8(1), 1-15. https://doi.org/10.1186/s40545-015-0044-4

Rutta, E., Senauer, K., Johnson, K., Adeya, G., Mbwasi, R., Liana, J., ... Alphonce, E. (2009). Creating a new class of pharmaceutical services provider for underserved areas: The Tanzania Accredited Drug Dispensing Outlet experience. Progress in Community Health Partnerships : Research, Education, and Action, 3(2), 145-153. https://doi.org/10.1353/cpr.0.0063

Samuels, P. (2016). Advice on Exploratory Factor Analysis. https://doi.org/10.13140/ RG.2.1.5013.9766

Seddon, P. B., \& Kiew, M. (1995). A partial test and development of Delone and Mclean's model of IS success. Australasian Journal of Information Systems, 4(1), 90-109. https://doi.org/http://dx.doi.org/10.3127/ajis.v4i1.379

Smith, A. D., \& Motley, D. (2010). Operational and customer relationship management considerations of electronic prescribing among pharmacists. International Journal of Electronic Healthcare, 5(3), 245. https://doi.org/10.1504/IJEH.2010.034175

US President's Malaria Initiative. (2017). Malaria Operational Plan FY 2017.

Vaghefi, I., \& Tulu, B. (2019). The continued use of mobile health apps: Insights from a longitudinal study. JMIR MHealth and UHealth, 7(8), 1-11. https://doi.org/10.2196/12983

Venkatesh, V., Morris, M. G., Hall, M., Davis, G. B., Davis, F. D., \& Walton, S. M. (2003). User acceptance of information technology : Toward a unified view. MIS Quarterly, 27(3), 425-478. https://doi.org/10.2307/30036540

Venkatesh, V., Thong, J. Y. L., \& Xu, X. (2012). Consumer acceptance and use of information technology: Extending the unified theory of acceptance and use of technology. MIS Quarterly, 36(1), 157-178. https://doi.org/10.2307/41410412 